\title{
Yoğun Bakım Ünitelerinde Fiziksel Tespit Kullanımı: Nedenler ve Sonuçlar $\infty$
}

\author{
Özge TURNA ${ }^{1}$, Ayla GÜRSOY²
}

\section{öz}

Amaç: Araştırma, cerrahi yoğun bakım ünitelerinde fiziksel tespit kullanım nedenlerini ve hastalarda görülebilecek sonuçlarını değerlendirmek amacıyla gerçekleştirildi.

Gereç ve Yöntem: Tanımlayıcı tipteki araştırma yoğun bakım ünitesinde fiziksel tespit uygulanan 81 hasta ve bu hastalara yapılan 1003 fiziksel tespit değerlendirmesini kapsamaktadır. Soru formları, Richmond Ajitasyon Sedasyon Ölçeği ve Glaskow Koma Ölçeği ile toplanan veriler Wilcoxon testi, Friedman testi, Mann Whitney $U$ testi ile analiz edildi.

Bulgular: Yoğun bakım ünitesindeki hastaların \%38.0'ine fiziksel tespit uygulandığı saptandı. Fiziksel tespite başvurma nedenleri arasında ilk sırada tıbbi ekipmanın çekilmesini önlemek (\%87.7) yer almaktadır. Fiziksel tespit uygulanan hastaların tespit süresi uzadıkça tespite bağı cilt ve davranışsal değişiklik gelişme sıklığının arttığı bulundu. Çalışmaya dahil edilen hastaların \%47.6'sında tespit bölgesinde cilt değişikliği gözlemlendi. Bu değişikliklerin en sık, ciltte kızarıklık (\%47.6), şişme/ödem (\%42.7) ve çökme (\%22.2) olduğu saptandı. Fiziksel tespit süresi uzadıkça hastaların ajitasyon düzeylerinin anlamlı şekilde azaldığı $(p=0.000)$, Glaskow Koma Ölçeği ortalama puanlarının ise arttığı saptandı $(\mathrm{p}=0.002)$.

Sonuç: Çalışma sonuçları hastaların kendisine zarar vermemesi amacıyla yapılan fiziksel tespitin hastaların konforunu olumsuz etkileyecek sorunlara yol açtığını göstermektedir. Tespit süresi uzadıkça sorunların arttığı sonucunu da gözeterek bu uygulamanın kararının çok dikkatli verilmesi ve tespit süresince hastaların düzenli değerlendirilmesi önerilir.

Anahtar kelimeler: Ajitasyon, fiziksel tespit, yoğun bakım, yoğun bakım hemşireliği

\begin{abstract}
Physical Restraint Use in Intensive Care Units: Causes and Consequences

Aim: This study was conducted to evaluate the reasons for using physical restraints in surgical intensive care units and the consequences that can be seen in patients.

Material and Methods: This descriptive study included 81 patients physically restrained in the intensive care unit and 1003 physical restraint evaluations made on these patients. The data collected by questionnaires, Richmond Agitation Sedation Scale and Glasgow Coma Scale were analyzed using Wilcoxon test, Friedman test, and Mann Whitney U test.

Results: Physical restraint was applied to $38 \%$ of the patients in the intensive care unit. Among the reasons for using physical restraint, the first is to prevent medical equipment removal (87.7\%). It was found that the longer the physical restraint time of the patients, the frequency of development of skin and behavioral changes due to restraint increased. Skin changes in the physical restraint area were observed in $47.6 \%$ of the patients. The most common changes were skin rash $(47.6 \%)$, swelling/edema (42.7\%), and collapse (22.2\%). It was found that as the physical restraint time increased, the agitation levels of the patients decreased significantly $(p=0.000)$, and the mean scores of the Glasgow Coma Scale increased $(\mathrm{p}=0.002)$.

Conclusion: The results of this study show that physical restraint made in order not to harm the patients themselves causes problems that will negatively affect the comfort of the patients. Considering the result that the problems increase as the physical restraint time increases, it is recommended to make the decision of physical restraint very carefully and to evaluate the patients regularly throughout the process.

Keywords: Agitation, intensive care, intensive care nursing, physical restraint
\end{abstract}

${ }^{1}$ Hemşire, Sağlık Bilimleri Üniversitesi Trabzon Kanuni Eğitim ve Araştırma Hastanesi, Anestezi Yoğun Bakım Ünitesi, Trabzon, Türkiye, E-posta:ozgekocakoglu@gmail.com, Tel: +90 46234156 56, ORCID:0000-0001-5816-2908

${ }^{2}$ Prof. Dr., Antalya Bilim Üniversitesi Sağlık Bilimleri Fakültesi, Hemşirelik Bölümü, Antalya, Türkiye, E-posta:aylagursoy68@gmail.com, Tel: +90 242 245 00 00, ORCID: 0000-0003-3585-4500

Geliş Tarihi: 27 Ocak 2020, Kabul Tarihi: 25 Ocak 2021

Atıf/Citation: Turna Ö, Gürsoy A. Yoğun Bakım Ünitelerinde Fiziksel Tespit Kullanımı: Nedenler ve Sonuçlar. Hacettepe Üniversitesi Hemşirelik Fakültesi Dergisi 2021; 8(2): 127-133. DOI: 10.31125/hunhemsire.966307 


\section{GíRiş}

Yoğun bakım, çoklu organ yetmezliği ya da organ sisteminde ciddi fizyolojik işlev bozukluğu nedeniyle, temel ve ileri yaşam destek tedavisi gerektiren hastalara verilen multidisipliner bakım ve tedavi şeklidir ${ }^{1}$. Yoğun bakım üniteleri ise bu özelliklerdeki hastaların tedavi edildiği ve sürekli gözlem altında tutulduğu bakım merkezleridir². Yoğun bakım ünitelerinde tedaviye yönelik birçok girişim uygulanmakta ve bu girişimler bireyi fizyolojik ve psikolojik olarak olumsuz yönde etkileyebilmektedir. Ayrıca bu ünitelerde istenmeyen sesler, yapay ışıklandırma, sosyal izolasyon gibi unsurlar hastalarda duyusal yüklenme ya da duyusal yoksunluk oluşturabilmektedir ${ }^{3,4}$. Yatağa bağımlı olma, hareket sınırlılığı, alışık olunmayan çevre, aile ve sosyal ortamdan uzak olma hastaların psiko-sosyal yönden olumsuz etkileyen diğer unsurlardır ${ }^{5-7}$. Bu faktörler hastalarda deliryum, konfüzyon, anksiyete ve ajitasyon oluşmasına da yol açmaktadır. Bunların sonucunda hastanın kendisine, çevresine zarar vermesi, yataktan düşmesi, tedavi ve bakım uygulamalarını reddetmesi gibi nedenlerle fiziksel tespit zorunluluğu ortaya çıkabilir ${ }^{8,9}$.

Fiziksel tespit, kendisine ya da çevresine zarar verme olasılığı durumunda, fiziksel ya da mekanik araçlarla hastanın hareketlerinin kısıtlanmasıdır. Tespitin amacı hastaların istenmeyen hareketlerinin kontrol altına alınması ve güvenliklerinin sağlanmasıdır ${ }^{10-12}$. Tespit uygulaması sedatize edilen hastaların derin sedasyondan hafif sedasyona geçişte güvenliğinin sağlanması amacıyla da kullanılmaktadır ${ }^{13}$

Fiziksel tespit yöntemi özellikle bakımevlerinde, psikiyatri, acil servis ve yoğun bakım ünitelerinde sıklıkla kullanılmaktadır ${ }^{14-17}$. Mısır'da hastanelerin yoğun bakım ünitelerinde yapılan bir çalışmada tespit oranı $\% 68$, Fransa'da ise bu oran $\% 82^{\prime}$ dir $^{14,18}$. Türkiye'de yoğun bakım ünitelerinde yapılan bir çalışmada ise hemşirelerin $\% 90.5$ 'inin çalıştıkları ünitelerde hastalara fiziksel tespit uygulandığını belirttikleri saptandı $\iota^{19}$.

Fiziksel tespit kararını en yaygın etkileyen unsurlar; düşme riski ya da düşme öyküsü, ileri yaş, saldırgan olma, şiddet öyküsü, iletişim kurmakta zorluktur. Ayrıca hastada var olan bilişsel değişiklikler ve günlük yaşam aktivitelerinde bağımlılık düzeyinin artması da fiziksel tespit kullanımını arttırmaktadır ${ }^{10,20-23}$.

Fiziksel tespit her ne kadar uygun yapılsa da hastanın konforunu olumsuz etkileyen bir uygulamadır. Tespit bölgesinde morarma, ödem, cilt erezyonu, tespite bağı doğrudan zarar; hastanın hareketsiz kalması, basınç yaralarının oluşması ya da artması ve mortalitede artış ise dolaylı zarar olarak değerlendirilmektedir ${ }^{24}$.

Yoğun bakım hastalarında hareket sınırlılığı duyusal yoksunluğa neden olabilmekte ve duygu durumunu değiştirmektedir ${ }^{25}$. Fiziksel tespit hastada var olan deliryum ve ajitasyon durumunu daha da arttırmaktadır. Bu uygulama hasta tarafından küçük düşürücü bir davranış olarak algılanabilmekte ve psikolojik travmaya sebep olabilmektedir ${ }^{18}$. Hastada kızıınlık, korku, panik, utanma duygularına neden olurken aynı zamanda tıbbi tedavi ve bakımı istememe ve sağlık ekibine güvenin azalmasına da neden olabilmektedir ${ }^{26}$.

Konu ile ilgili kaynaklarda; yoğun bakım ünitelerinde fiziksel tespit nedenleri ve fiziksel tespitin hasta üzerindeki etkileri ile ilgili çalışmalar bulunmaktadır ${ }^{11,14,16}$. Ancak ülkemizde konuya ilişkin yoğun bakım ünitelerinde yapılan çalışmalar sınırlıdır ve yapılan çalışmalarda da tespitin hasta üzerindeki etkileri doğrudan değerlendirme olmayıp, kayıtlardan elde edilen sonuçlardır.

\section{Araştırmanın Amacı}

Araştırma cerrahi yoğun bakım ünitelerinde fiziksel tespit uygulamalarının hangi durumlarda kullanıldığı, kullanılma nedenleri, kullanılan fiziksel tespit yöntemleri ve fiziksel tespitin hastadaki sonuçlarını değerlendirmek amacıyla gerçekleştirildi.

\section{GEREÇ ve YÖNTEM \\ Araştırmanın Türü}

Çalışma tanımlayıcı tiptedir.

\section{Araştırma Evren ve Örneklemi}

Araştırma 16.10.2017-16.01.2018 tarihleri arasında Doğu Karadeniz Bölgesi'ndeki bir ilin devlet hastanesinin cerrahi ve anestezi yoğun bakım ünitesinde yürütüldü. Bir yıl içinde hastanenin cerrahi ve anestezi yoğun bakım ünitesine 980 hasta kabul edilmektedir ancak kaç hastaya fiziksel tespit uygulandığına ilişkin kayıt bulunmamaktadır.

Yoğun bakımda iken fiziksel tespit uygulanan ve 18 yaşından büyük olan hastalar örnekleme kabul edildiler. Zihinsel kısıtlııı, 30 dakikadan daha kısa süre tespit uygulanması varlığı, sağlık ekibi tarafından bedeni tutularak hareketi engellenmek üzere gerçekleştirilen tespit uygulamaları, fiziksel tespit bölgesinde tespitten önce ödem, hematom, kızarıklık, cilt nekrozu gibi değişiklik varlığı ise örneklem dışlanma ölçütleri olarak belirlendi. Üç aylık süre içinde araştırmanın yapıldığı yoğun bakıma 376 hasta yatırıldı ve bu hastalardan 143'üne fiziksel tespit uygulandığı saptandı. Fiziksel tespit bölgesinde tespitten önce hematom, ödem, kızarıklık ve cilt erezyonu gibi değişiklikler olduğu için 62 hasta örneklem dışı bırakıldı. Çalışma kabul ölçütlerini karşılayan ve fiziksel tespit uygulaması gerçekleştirilen 81 hasta ile tamamlandı. Her hasta tespit anından, tespit sonlanana kadar değerlendirildi. Bu doğrultuda çalışmada toplam 1003 fiziksel tespit uygulamasının değerlendirilmesi gerçekleştirildi.

\section{Veri Toplama Araçları}

Çalışmada veriler Glasgow Koma (GKÖ) ve Richmond Ajitasyon Sedasyon Ölçekleri (RASÖ) ile toplandı. Ölçeklerin yanı sıra veri toplamak için ilgili kaynaklar doğrultusunda araştırmacılar tarafından hazırlanan soru formları kullanıldı14,15,19,27,28

\section{Glasgow Koma Ölçeği (GKÖ)}

Ölçek Glasgow Üniversitesi Nörolojik Bilimler Enstitüsü beyin cerrahisi profesörleri Graham Teasdale ve Bryan J. Jennett tarafından 1974 yılında oluşturulmuştur. Glasgow koma ölçeği; göz açma, sözlü, motor olmak üzere üç değişkeni değerlendirmektedir. Her değişken için belirli bir puan verilmektedir. Ölçek toplam puanı 15 ise hasta oryante, $13-14$ ise konfüze, $8-13$ ise stupor, $3-8$ ise perikoma, 3 'ün altında ise koma olarak tanımlanmaktadır ${ }^{29}$. 
Ölçek yoğun bakımlarda bilinç değerlendirmesi için yaygın olarak kullanılmaktadır. Çalışmada ölçek, fiziksel tespit uygulamasının hastaların bilinç durumuna etkisini belirlemek amacıyla kullanıldı.

\section{Richmond Ajitasyon Sedasyon Ölçeği (RASÖ)}

Ölçek Richmond Virginia Commonwealth Üniversitesi tarafından geliştirilmiştir. Toplam puanı 10 olan ölçekte hastanın ajitasyonu +4 (Hırçın; personel için tehlikeli olabilecek düzeyde) ile -5 (uyandırılamaz) aralığında puanlanmaktadır. Puanlama; +4 kavgacı, +3 çok ajite, +2 ajite, +1 huzursuz, 0 sakin/uyanık, -1 uykulu, -2 hafif sedasyon, -3 orta sedasyon, -4 derin sedasyon ve -5 koma şeklinde yapılmaktadır ${ }^{30}$. Bu ölçek fiziksel tespit uygulamalarının hastaların ajitasyon durumuna etkisini değerlendirmek için kullanıldı.

\section{Demografik ve Klinik Özellikler Formu}

Demografik ve klinik özellikler formunun ilk kısmın demografik bilgileri içeren (yaş, cinsiyet, beden kitle indeksi) üç soru oluşturmaktadır. İkinci kısımda ise tıbbi durumuna ilişkin bilgileri içeren (görme kaybı, işitme kaybı, ziyaretçi durumu, yoğun bakımda kalış süresi, primer tanı, ek hastalık, hasta grubu, invaziv araç-gereç varlığı, analjezik kullanımı ve sedatif kullanımı) on soru yer almaktadır.

\section{Fiziksel Tespit Formu}

Form fiziksel tespit nedenleri, türü, tespit için kullanılan araç, tespit süresi, tespit uygulama kararı, alternatif yöntem kullanım durumunu belirleyen altı sorudan oluşmaktadır.

\section{Fiziksel Tespiti Olan Hasta Değerlendirme Formu}

Form fiziksel tespit uygulanan hastaların cilt ve davranış değişikliklerini belirlemeye yöneliktir. Fiziksel tespit bölgesi ile ilgili cilt değişiklikleri (sorun gelişmedi, kızarıklık, siyanoz, ülserasyon, şişme/ödem, cilt nekrozu, cilt erezyonu, diğer) ve davranış değişiklikleri (ajitasyon artışı, oryantasyon/sakinlik, ağlama/inleme, diğer) olmak üzere iki alt grupta toplam 12 madde içermektedir.

Fiziksel tespit ve fiziksel tespiti olan hasta değerlendirme formu kapsam geçerliliği için iki hemşire öğretim üyesi ve bir istatistikçiden uzman görüşü alındı. Daha sonra on hastada ön uygulama yapıldı ve bu hastalar araştırma kapsamına alınmadı. Ön uygulama sonucunda veri toplama formlarında gerekli değişiklikler yapıldı.

\section{Veri Toplama Araçlarının Uygulanması}

Klinik değerlendirmenin tespit başladıktan sonlanana kadar kesintisiz devam etmesi gerekmekteydi. Ancak yazarların 24 saat hastanede olmaları mümkün olmadığı için fiziksel tespiti olan hasta değerlendirme formunun uygulanmasında altı hemşire (anestezi yoğun bakım ünitesinde üç ve cerrahi yoğun bakım ünitesinde üç) görev aldı. Klinik değerlendirmenin nasıl yapılacağı ve kaydedileceği konusunda ilk yazar tarafından hemşirelere bireysel olarak 30 dakikalık bilgilendirme yapıldı. Ayrıca değerlendirme yapacak olan her hemşirenin ilk üç değerlendirmesi ilk yazar ile yapıldı.

Her hastanın tespitten önce, tespit bölgesi cildi (kızarıklık, yara, ödem vb.) ve davranışsal durumu değerlendirildi. Daha sonra tespit sonlanana kadar fiziksel tespiti olan hasta değerlendirme formu ile hastanın tespit bölgesindeki cildi, duyusal/davranışsal değişiklikleri ve RASÖ ile ajitasyon durumu değerlendirildi. İlki tespit anında olmak üzere ilk 12 saat hastalar iki saatte bir değerlendirildi. On iki saati aşan tespitlerde ise tespit sonlanana kadar her hasta için standart izlem akışı belirlendi. En az iki, en fazla 62 olmak üzere ortalama dokuz gözlem yapıldı. Tespiti olan hasta izlem akışı aşağıdaki şemada gösterilmektedir.

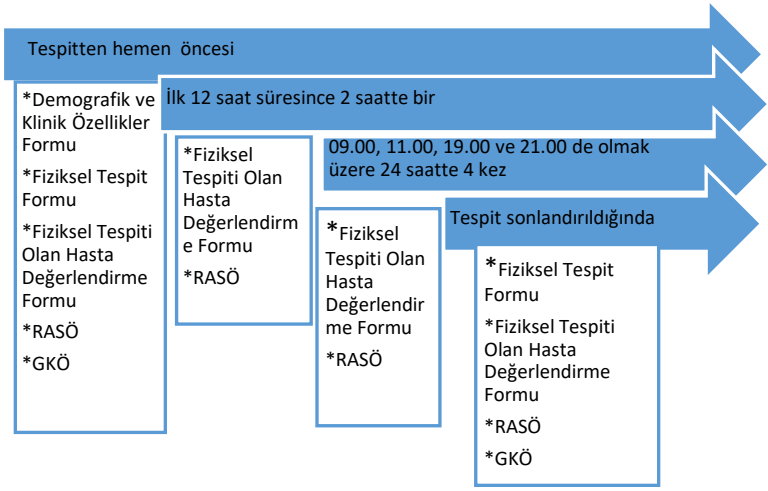

Şema 1. Tespiti olan hasta değerlendirme akışı

\section{Verilerin Analizi}

Elde edilen verilerin değerlendirilmesinde SPSS 23.0 (Statistical Package of Social Sciences) paket programı kullanıldı. Fiziksel tespit öncesi ve fiziksel tespit sonrası GKÖ ve RASÖ ortalama puanlarının analizinde Wilcoxon testi, tespite bağlı sorun gelişen ve gelişmeyen hastaların RASÖ ortalama puanlarının analizinde ise Friedman testi ve Mann Whitney U testi kullanıldı.

\section{Araştırmanın Etik Boyutu}

Araştırma için Bölge Bilimsel Araştırmalar Kurulu Başkanlığından 18.11.2016'da etik kurul izni (Sayı:23618724-000-13946) ve araştırmanın yapıldığı hastaneden 02.09.2016'da çalışma izni (Sayı: 29765155/799-E.9827) alındı. Araştırma kapsamına alınan hastaların bilinç durumu sözel ya da yazılı izin almaya uygun olmadığı için çalışma izni birinci derece bir yakınından alındı.

\section{Araştırmanın Sınırlılıkları}

Hastayı tespit etmeye çalışırken gerçekleşmiş olabilecek cilt değişikliklerini (kızarma, sıyrık, morarma vb.) belirlemenin mümkün olmaması çalışmanın sınırlılıklarından biridir. Bunun yanı sıra yoğun bakım hastaları çoklu sağlık sorununa sahip hastalardır. Fiziksel tespit dışında bu sorunların da hastalarda cilt ve davranış değişikliklerine yol açma olasılığı çalışmanın diğer sınırlılığıdır.

\section{BULGULAR}

Hastalar ortalama 70.3 (SS:17.4) (min:19, mak:102) yaşında olup \%65.4'ü erkektir. Hastaların tanıları arasında en sık solunum (\%29.6), beyin ve sinir sistemi hastalıkları (\%17.2) yer almaktadır. Hastaların klinik tanılarına eşlik eden hastalıklar arasında ise en sık karşılaşılanlar hipertansiyon (\%37), diyabet (\%25.9) ve kalp hastalıkları (\%23.4)'dır. Hastaların beden kitle indeksine göre \%66.7'si normal kilodadır.

Araştırmaya katılan hastaların tamamında (\%100) en az bir invaziv girişim yapılmıştır. İnvaziv girişimler içinde en sık kullanılan foley kateterdir (\%95.1). Entübasyon tüpü (\%44.4), santral venöz kateter (\%27.2), nazogastrik sonda (\%25) ve toraks tüp (\%14.8) ise diğer tıbbi araçlar arasında en çok kullanılanlardır. 
Çalışma kapsamındaki hastaların \%95.1'inde fiziksel tespit kararının hemşire tarafından verildiği bulundu. Araştırmanın süresince yoğun bakıma yatırılan \%38.0'ine fiziksel tespit uygulandığı saptandı. Fiziksel tespit uygulamalarına ilişkin tanımlayıcı bilgiler Tablo 1'de görülmektedir.

Tablo 1. Tablo 1. Fiziksel Tespit Uygulamalarına Iliş̧in Tanıtıcı Bilgiler $(n=81)$

\begin{tabular}{|c|c|c|}
\hline Bilgiler & n & $\%$ * \\
\hline \multicolumn{3}{|l|}{ Tespit nedenleri } \\
\hline Tıbbi ekipmanın çekilmesini önlemek & 71 & 87.7 \\
\hline Ajitasyon & 45 & 55.6 \\
\hline Kendine zarar vermeyi önlemek & 36 & 44.4 \\
\hline Dezoryantasyon-konfüzyon & 33 & 40.7 \\
\hline Yataktan düşmeyi önlemek & 29 & 35.8 \\
\hline Tıbbi girişimde bulunmak & 17 & 21.0 \\
\hline Ekstremitelerde kontraktür gelişmesini engellemek & 5 & 6.2 \\
\hline $\begin{array}{l}\text { Sedasyon etkisinden çıkarken uygunsuz } \\
\text { davranışları engellemek }\end{array}$ & 4 & 4.9 \\
\hline \multicolumn{3}{|l|}{ Tespit türü } \\
\hline Üst ekstremite & 81 & 100.0 \\
\hline Çift taraflı & 65 & 80.2 \\
\hline Tek taraflı & 16 & 19.8 \\
\hline Alt ekstremite & 22 & 27.2 \\
\hline Çift taraflı & 70 & 86.4 \\
\hline Tek taraflı & 11 & 13.6 \\
\hline Tüm vücut & 10 & 12.3 \\
\hline \multicolumn{3}{|l|}{ Tespit aracı } \\
\hline Pamuklu sünger dolgulu bileklik & 81 & 100.0 \\
\hline Bedensel tespit materyali & 10 & 12.3 \\
\hline \multicolumn{3}{|l|}{ Tespit süresi } \\
\hline 24 saatten az & 36 & 44.4 \\
\hline $1-2$ gün & 18 & 22.2 \\
\hline 3-4 gün & 9 & 11.1 \\
\hline 4 günden fazla & 18 & 22.2 \\
\hline \multicolumn{3}{|l|}{ Tespite karar veren } \\
\hline Tedaviden sorumlu hemşire & 77 & 95.1 \\
\hline Tedaviden sorumlu hekim ve hemşire & 4 & 4.9 \\
\hline Tedaviden sorumlu hekim & 0 & 0 \\
\hline \multicolumn{3}{|l|}{ Tespit öncesi kullanılan diğer yöntemler } \\
\hline Kullanılmadı & 55 & 67.9 \\
\hline Farmakolojik yöntemleri uygulama & 26 & 32.1 \\
\hline \multicolumn{3}{|l|}{ Tespit sonlandırıldığında kullanılan diğer yöntemler } \\
\hline Kullanılmadı & 64 & 79.0 \\
\hline Farmakolojik yöntemleri uygulama & 16 & 19.8 \\
\hline Hasta yakınlarından yardım alınması & 1 & 1.2 \\
\hline $\begin{array}{l}\text { Hastanın daha rahat gözlemlenebileceği bir yatağa } \\
\text { alınması }\end{array}$ & 1 & 1.2 \\
\hline
\end{tabular}

*Bir hastada birden fazla fiziksel tespit nedeni, türü, materyali ve tespit sonrası kullanılan yöntem olduğu için $n$ katlandı. Ancak yüzdeler $n=81$ üzerinden alındı.

Yapılan tespit değerlendirmelerinin \%47.6'sında tespit bölgesinde ciltte değişiklik geliştiği saptandı. Kızarıklık (\%42.9) ve şişme/ödem (\%42.7) yirmi dört saat içinde en sık karşılaşılan cilt sorunlarıydı. Tespitten sonra hastaların \%33.4'ünde davranışsal değişim belirlendi (Tablo 2).

Tespite bağlı cilt değişikliği gelişen hastaların \%62.9'unun 4 gün ve üzeri tespit uygulanan hastalar olduğu belirlendi (Tablo 3).
Tablo 2. Hastalarda Tespit Sonrası Cilt ve Davranış Değişiklikleri ( $\mathrm{n}=$ 1003 değerlendirme)

\begin{tabular}{|c|c|c|c|c|c|c|}
\hline \multirow[t]{2}{*}{ Değişiklikler } & \multicolumn{2}{|c|}{$\begin{array}{l}08-16 \\
(\mathrm{n}: 518 \\
\text { değerlendirme) }\end{array}$} & \multicolumn{2}{|c|}{$\begin{array}{l}16-08 \\
(\mathrm{n}: 485 \\
\text { değerlendirme) }\end{array}$} & \multicolumn{2}{|c|}{$\begin{array}{l}24 \text { saat içinde } \\
\text { ( } \mathrm{n}: 1003 \\
\text { değerlendirme) }\end{array}$} \\
\hline & n* & $\%$ & n* & $\%$ & n* & $\%$ \\
\hline \multicolumn{7}{|c|}{ Tespit bölgesindeki cilt değişiklikleri* } \\
\hline Değişiklik yok & 228 & 44.0 & 298 & 61.4 & 526 & 52.4 \\
\hline Kızarıklık & 134 & 46.2 & 71 & 37.9 & 205 & 42.9 \\
\hline Şişme/ödem & 139 & 47.9 & 65 & 34.7 & 204 & 42.7 \\
\hline Ciltte çöküntü & 79 & 27.2 & 27 & 14.4 & 106 & 22.2 \\
\hline Siyanoz & 48 & 16.5 & 18 & 9.6 & 66 & 13.8 \\
\hline Ülserasyon & 11 & 3.7 & 2 & 1.0 & 13 & 2.7 \\
\hline Cilt erezyonu & 8 & 2.7 & 6 & 3.2 & 14 & 2.9 \\
\hline \multicolumn{7}{|c|}{ Davranışsal değişiklikler } \\
\hline Değişiklik yok & 337 & 65.0 & 331 & 68.2 & 668 & 66.6 \\
\hline Sakinleşme & 73 & 40.3 & 76 & 49.3 & 149 & 44.4 \\
\hline Ajitasyon artışı & 67 & 37.0 & 59 & 38.3 & 126 & 37.6 \\
\hline Ağlama/inleme & 31 & 17.1 & 8 & 5.1 & 39 & 11.6 \\
\hline \multicolumn{7}{|c|}{$\begin{array}{l}\text { *Bir hastada fiziksel tespit bölgesi ile ilgili birden fazla değişiklik görüldüğü için } n \text { katlandı. } \\
\text { Tablo 3. Fiziksel Tespit Uygulama Süresine Göre Hastalarda Tespit } \\
\text { Bölgesinde Cilt Değişikliği Gelişme Durumu ( } \mathbf{n = 1 0 0 3 )}\end{array}$} \\
\hline \multirow{3}{*}{ Süre } & \multicolumn{4}{|c|}{\begin{tabular}{|c|} 
Değişiklik \\
\end{tabular}} & \multicolumn{2}{|c|}{ Toplam } \\
\hline & \multicolumn{2}{|c|}{ Gelişti } & \multicolumn{2}{|c|}{ Gelişmedi } & & \\
\hline & $\mathbf{n}$ & $\%$ & $\mathbf{n}$ & $\%$ & $\mathbf{n}$ & $\%$ \\
\hline 24 saatten kısa & 40 & 8.7 & 151 & 27.7 & 191 & 19.1 \\
\hline 1-2 gün & 52 & 11.4 & 93 & 17.1 & 145 & 14.4 \\
\hline 3-4 gün & 78 & 17.0 & 53 & 9.7 & 131 & 13.1 \\
\hline 4 günden fazla & 288 & 62.9 & 248 & 45.5 & 536 & 53.4 \\
\hline Toplam & 458 & 100.0 & 545 & 100.0 & 1003 & 100.0 \\
\hline
\end{tabular}

Hastaların fiziksel tespit sonrası GKÖ ortalama puanlarının fiziksel tespit öncesi değerlendirmelere göre anlamlı şekilde yüksek olduğu bulundu ( $p=0.002$ ). Fiziksel tespit sonrası RASÖ ortalama puanının ise tespit öncesine göre düşük olduğu olduğu belirlendi $(p=0.000)$ (Tablo 4$)$.

Tablo 4. Fiziksel Tespit Öncesi ve Sonrası GKÖ ve RASÖ Ortalama Puanları $(n=81)$

\begin{tabular}{|l|l|l|l|}
\hline & $\begin{array}{l}\text { Tespit öncesi } \\
\overline{\mathbf{X}} \pm S S, \text { ortanca, } \\
(\mathbf{m i n} / \mathrm{mak})\end{array}$ & $\begin{array}{l}\text { Tespit sonrası } \\
\overline{\mathbf{X}} \pm \text { SS,ortanca, } \\
\text { (min/mak) }\end{array}$ & $\begin{array}{l}\text { İstatistik } \\
\text { değeri } \\
\mathbf{P}\end{array}$ \\
\hline GKÖ & $10.4 \pm 2.6,10,(3 / 15)$ & $11.6 \pm 3.713,(3 / 15)$ & $\mathrm{p}=0.002$ \\
\hline RASÖ & $1.3 \pm 1.6 .2,(-4 /+4)$ & $0.1 \pm 1.6,0,(-5 /+4)$ & $\mathrm{P}<0.001$ \\
\hline
\end{tabular}

\section{TARTIŞMA}

Fiziksel tespit farklı kliniklerde hastanın üzerindeki ekipmanları çekmesini ya da kendisine zarar vermesini önlemek amacıyla kullanılan bir yöntemdir. Özellikle bilinç durumları ve kendilerine uygulanan tedaviye bağı olarak fiziksel tespite en sık başvurulan ünitelerden biri de yoğun bakımlardır. Hastanın yararı için uygulanan fiziksel tespitin uzun süreli ve uygun olmayan kullanımı hastalarda psikolojik ve fiziksel sorunlara yol açabilmektedir ${ }^{31}$. Bu nedenle fiziksel tespit kararının titizlikle verilmesi ve tespit edilen hastaların dikkatli ve kapsamlı izlenmesi gerekmektedir.

$\mathrm{Bu}$ araştırmada, veri toplama süreci içinde yoğun bakımda yatan hastaların üçte birinden fazlasına fiziksel tespit uygulandığı bulundu. Yoğun bakım ünitelerinde yapılan diğer çalışmalarda da bu oran \%39.1 ile \%82 arasındadır ${ }^{14,18,28,32,33}$. Türkiye'de yoğun bakım ünitelerinde yapılan bir çalışmada ise hemşirelerin \%90.5'inin fiziksel tespit uyguladığı belirtilmiştir ${ }^{19}$. Yoğun bakım ünitesi hastaları var olan hastalıklarından ve yoğun bakım ortamının 
etkisinden dolayı daha çok bilinç karmaşası yaşamaktadır. $\mathrm{Bu}$ ünitelerde tespite başvurma oranının diğer ünitelere göre daha fazla olması bu duruma bağlanabilir.

Çalışmamızda fiziksel tespite başvurma nedenleri arasında tıbbi ekipmanın çekilmesini önlemek, ajitasyon ve kendine zarar vermeyi önlemek en başta yer almaktadır. Kooi ve arkadaşlarının (2015) yoğun bakımlarda yaptıkları çalışmada da ilk sırada tüp ve kateterlerin çekilmesini önlemek amacıyla fiziksel tespit uygulandığı bulunmuştur ${ }^{34}$. Karagözoğlu ve arkadaşlarının (2014) çalışmasında hemşirelerin \%82.5'inin hastaya bağı olan tüplerin hasta tarafından çıkarılmasını önlemek amacıyla tespit uyguladığı belirlenmiştir ${ }^{35}$. Hastaların ekipmanları çekmesini önlemek bizim çalışmamız ve diğer çalışmalarda ortak sonuçtur.

Hastaların tamamına üst ekstremite bilek tespiti yapıldığı ve bunlardan çoğunun çift taraflı olarak yapıldığı belirlendi. Fiziksel tespit aracı olarak tüm hastalarda pamuklu sünger dolgulu bileklik kullanıldığı görüldü. Kısacık ve arkadaşının (2019) çalışmasında \%59.8 oranında çift tarafı üst ekstremite bilek tespiti, \%16.7 oranında ise tek taraflı üst ekstremite bilek tespiti uygulanmıştır ${ }^{36}$. Gu ve arkadaşlarının (2019) yaptığı çalışmada benzer olarak üst ekstremite çift taraflı bilek tespit oranı \%56.5' dir, tek taraflı üst ekstremite bilek tespiti ise $\% 17^{\prime}$ dir $^{33}$. Bu araştırmalardaki ve çalışmamızda elde ettiğimiz sonuçlar hastalara uygulanan en yaygın yöntemin çift üst ekstremite bilek tespiti olduğunu göstermektedir.

Araştırma kapsamına alınan hastaların yaklaşık olarak yarısının 24 saatten az tespit edildiği belirlendi. Kandeel ve Attia'nın (2013) çalışmasında 24 saatten daha kısa sürede tespit edilen hastaların oranları çalışmamızdan daha düşük (\%3.3) iken 3-4 gün tespitli kalan hastaların oranları ise çalışmamızdan daha yüksektir $(\% 58.8)^{14}$. Bu farklılık çalışmanın yapıldığı yoğun bakımda cerrahi sonrası olan hastaların fazla sayıda olmasına bağlanabilir. Anestezi etkisi geçtiğinde hastaların tespitlerinin sonlandırıldığı bu nedenle sürenin diğer çalışmalardan daha kısa olduğu düşünülebilir. $\mathrm{Bu}$ çalışmada hastaların fiziksel tespit uygulama kararını çoğunlukla hemşirelerin verdiği belirlendi. Yapılan diğer çalışmalarda da fiziksel tespit uygulama kararını genellikle hemşirelerin verdiği belirtilmektedir ${ }^{31,37,38}$. Hastayı en yakından izleyen sağlık profesyoneli olmaları nedeniyle hastanın kendisine zarar vermesinin önlenmesinde kritik rol üstlenmektedirler. Hastanelerde fiziksel tespit uygulamasını azaltmak için farklı yöntemler kullanılabilir. Bunlar arasında hastanın sakinleşmesi amacı ile farmakolojik yöntemleri uygulamak ya da hastanın yakınlarından yardım alınması ve hastanın daha rahat gözlemleneceği bir yatağa alınması yer almaktadır ${ }^{32,39}$. Çalışmada hastaların yaklaşık yarısından fazlasında fiziksel tespit uygulanmadan önce herhangi bir farklı yöntem kullanılmadığı saptandı. Farklı yöntem kullanılan hastalarda ise farmakolojik yöntem uygulandığı ancak yeterli olmadığı için tespit işlemi başlatıldığı belirlendi. Fiziksel tespit uygulandıktan sonra ise hastaların yaklaşık dörtte üçünde farklı yöntem kullanılmadığı bulundu. Kooi ve arkadaşlarının (2015) çalışmasında farmakolojik yöntemleri kullanmanın fiziksel tespit kullanımını önemli ölçüde azalttığı belirtilmektedir ${ }^{34}$. Eşer ve arkadaşlarının (2007) çalışmasında fiziksel tespit uygulanan hastaların \%74.8'ine farklı yöntem uygulanmıştır. Bu çalışmada en fazla kullanılan farklı yöntemin hasta ile konuşmak olduğu belirtilmiştir ${ }^{28}$.

Hastalarda tespite bağlı ciltte değişikliklerin sabah vardiyasında daha çok geliştiği belirlendi. Kandeel ve Attia'nın (2013) çalışmasında ise hastalarda gece vardiyasında daha çok ciltte değişiklik geliştiği belirtilmiştir ${ }^{14}$. Gece vardiyalarında hemşire sayısının, bakımın ve gözlemin daha az olmasına bağlı cilt değişikliklerinin artması beklenilebilir. Çalışmamızda sonucun farklı çıkması tespiti başlatma saatindeki farklılıklar, hastaların klinik seyrindeki değişimler, özellikle gündüz yapılan yoğun tedavi ve bakıma karşı daha fazla direnç göstermelerinden kaynaklanabilir.

Çalışma kapsamındaki hastaların yaklaşık yarısında tespit bölgesinde ciltte değişiklik geliştiği saptandı. En sık karşılaşılan cilt değişikliklerinin; kızarıklık ve şişme/ödem olduğu belirlendi. Kandeel ve Attia'nın (2013) çalışmasında bizim çalışmamıza benzer olarak fiziksel tespit uygulanan hastalarda gelişen cilt değişiklikleri arasında ilk sırada kızarıklık (\%16.5) olduğu belirtilmiştir ${ }^{14}$. Eşer ve arkadaşlarının (2007) Türkiye'de gerçekleştirdikleri araştırmada ise cilt değişiklikleri arasında bu çalışmadan farklı oranlarda olarak; siyanoz (\%40.9), ödem (\%31.9), kızarıklık (\%13.6) bulunmaktadı2 ${ }^{28}$. Bu farklılıklar kullanılan tespit malzemesi, hastaların cilt yapıları ve sağlık ile ilgili durumları ve tespitin hasta konforuna ne kadar uygun olarak yapıldığına bağlı olarak değişebilir.

Tespitten sonra hastaların yaklaşık üçte birinde davranış değişiklikleri belirlendi. Bu değişiklikler sakinleşme, ajitasyon artışı ve ağlama/inleme şeklindedir. Yapılan diğer çalışmalarda hastalarda gelişen davranışsal değişiklikler oranları farklı olmakla birlikte aynıdır ${ }^{14,36}$. Bu sonuçlar bize fiziksel tespit uygulamasının hastanın davranışsal durumuna etkisinin benzer olduğunu göstermektedir.

Araştırmada dört günden daha uzun süre tespit edilen hastaların yaklaşık yarısında, 24 saatten daha kısa süre tespit edilen hastaların ise sadece dörtte birinde değişiklik geliştiği belirlendi. Bu sonuç tespit süresi uzadıkça değişiklik gelişme sıklığının arttığını göstermektedir. Yapılan çalışmalarda da uzun süreli fiziksel tespit kullanımının hastalar üzerinde olumsuz etkilere sebep olabileceği belirtilmiştir11,31,37.

Araştırmada fiziksel tespit sonlandırıldıktan hemen sonra bakılan hastaların GKÖ ortalama puanının, tespit öncesinden yüksek olduğu bulundu. Fiziksel tespit öncesi hastaların GKÖ puanlarının düşük olması konfüzyon ya da sedasyona bağlı olabilmektedir. Fiziksel tespit, hastalar sakinleşip, yer-zaman oryantasyonu kazandıklarında sonlandırılmaktadır. Bunun yanı sıra eş zamanlı sedasyon uygulaması da sonlandırılmaktadır. Bu nedenle hastaların tespit sonrası GKÖ puanlarının yüksek ajitasyon puanlarının ise düşük olması beklendik bir sonuçtur. $\mathrm{Gu}$ ve arkadaşlarının (2019) yoğun bakım ünitelerinde yaptıkları çalışmada da fiziksel tespit uygulanan hastalarda GKÖ ortanca değeri (12) fiziksel tespit uygulanmayan hastalardan (15) daha düşük bulunmuştur ${ }^{33}$.

Araştırmamızda hastaların tespit sonrası ajitasyon puanlarının fiziksel tespit öncesinden düşük olduğu belirlendi. Fiziksel tespit öncesi hastanın ajitasyon puanının 
yüksek olması, hastanın ajitasyonu olduğunu ve tıbbi ekipmanı çekebilme riskinin olmasından dolayı tespit edildiğini düşündürmektedir. Tespit sonlandırımadan önce bakılan son RASÖ puanının düşük olması ise hastanın sakinleştiği ve artık tıbbi ekipmanı çekme ve kendine zarar verme riski olmadığını göstermektedir. Kooi ve arkadaşlarının (2015) yoğun bakım ünitelerinde yaptıkları çalışmada ise fiziksel tespit uygulanan hastalarda RASÖ ortanca değerinin bizim sonuçlarımızdan çok daha düşük olduğu bulunmuştur ${ }^{34}$. Bu sonucun araştırmamızdan elde ettiğimiz sonuç ile benzerlik göstermemesinin nedeni fiziksel tespit uygulanan hastaların sağlık durumu ve kullanılan sedasyon çeşidinin, miktarının farklı olmasına bağlanabilir.

\section{SONUÇ ve ÖNERILER}

Yoğun bakım ünitelerinde fiziksel tespit uygulaması sıklıkla kullanılmaktadır. Ancak bu uygulamanın hastanın yararı gözetilerek yapılması ve olabilecek en kısa süre içerisinde sonlandırılması gerekmektedir. Bunun yanı sıra tespitin vereceği zararı en aza indirmek için hastanın ve tespit bölgesinin düzenli kontrolünün sağlanması önemlidir. Fiziksel tespit uygulamasına bağlı cilt sorunlarının azaltılması için en az kısıtlayıcı tespit yöntemi ve aracı kullanılmalıdır. Tespiti mümkün olan en kısa sürede sonlandırmak için hasta sık sık değerlendirilmeli ve kullanılabilecek farklı yöntemler düşünülmelidir. Fiziksel tespit kararının doğru verilmesi, hastanın gözlenmesi, sorunların erken fark edilmesi ve tespitin sonlandırılmasında tüm ekibin önemli sorumlulukları bulunmaktadır. Bu bağlamda ekip üyelerinde bu anlayışın yerleşmesine yönelik etkinlikler yapılabilir. Ayrıca fiziksel tespite seçenek olabilecek ve süresini kısaltacak yöntemler için araştırmalar yapılması önerilir.

Etik Kurul Onayı: Bölge Bilimsel Araştırmalar Kurulu Başkanlığından alınmıştır. (Tarih:18.11.2016, Sayı:23618724-000-13946).

Çıkar Çatışması: Yoktur.

Finansal Destek: Bildirilmemiştir.

Katılımcı Onamı: Araştırma kapsamına alınan hastaların bilinç durumu sözel ya da yazııı izin almaya uygun olmadığı için çalışma izni birinci derece bir yakınından alındı.

Yazar katkıları:

Araştırma dizaynı: ÖT, AG

Veri toplama: ÖT

Literatür araştırması: ÖT, AG

Makale yazımı: ÖT, AG

Teşekkür

Fiziksel tespiti olan hasta değerlendirme formunun uygulanmasında yardımcı olan hemşire arkadaşlarımıza teşekkür ederiz.

Ethics Committee Approval: Approval was obtained from the Regional Scientific Research Board (Date: 18.11.2016, Decision Number: 23618724-000-13946).

Confict of Interest: Not reported.

Funding: None.

Exhibitor Consent: Since the state of consciousness of the patients included in the study was not suitable for verbal or written approval, the study permit was obtained from a first degree relative.

\section{Author contributions:}

Study design: OT, AG

Data collection: OT

Literature search: OT, AG

Drafting manuscript: $\mathrm{OT}, \mathrm{AG}$

Acknowledgement: We would like to thank the nurses who helped in applying the evaluation form for patients with physical restraint.

\section{KAYNAKLAR}

1. Çelik MG, Altan A. Yoğun Bakım Hemşireliği. Ankara. Güneş Tıp Kitapevleri. 2019.s.4-9.

2. Varon J, Acosta P. Approach to the intensive care unit (ICU). In: Handbook of critical care and intensive care medicine. 2nd ed. Springer; 2010. p.1-10.

3. Aslan FE, Olgun N. Yoğun bakım ortamı. Aslan FE, Çakır M, editörler. Yoğun Bakım: Seçilmiş Semptom ve Bulguların Yönetimi. Ankara: Akademisyen Kitabevi; 2016. s.3-14.

4. Tuncay GY, Uçar H. Hastaların yoğun bakım ünitesinin fiziksel ortam özelliklerine ilişkin görüşleri. Hacettepe Üniversitesi Sağlık Bilimleri Fakültesi Hemşirelik Dergisi 2010;33-46.

5. Luk E, Burry L, Rezaie S, Mehta S, Rose L. Critical carenurses' decisions regarding physical restraints in two Canadian ICUs: A prospective observational study. Can J Crit Care Nurs.2015;26(4):16-22.

6. Uzelli D, Korhan EA. Yoğun bakım hastalarında duyusal girdi sorunları ve hemşirelik yaklaşımı. Florence Nightingale Hemşirelik Dergisi.2014;22(2):120-128.

7. Terzi B, Kaya N. Yoğun bakım hastasında hemşirelik bakımı. Yoğun Bakım Dergisi. 2011;1:21-25.

8. Perez D, Peters K, Wilkes L, Murphy G. Physical restraints in intensive care: An integrative review. Australian Critical Care. 2019;32:165-174.

9. Birgili F, İzan F. The Knowledge, Attitudes and Practices of Nurses in Relation to the Use of Physical Restraints. International Journal of Health Sciences. 2019;7:18-25.

10. Möhler R, Richter T, Köpke S, Meyer G. Interventions for preventing and reducing the use of physical restraints in long-term geriatric care - a Cochrane review. J Clin Nurs. 2012;21(21-22):3070-3081.

11. Kaya H, Aştı T, Acaroğlu R, Erol S, Savcı C. Hemşirelerin fiziksel tespit edici kullanımına ilişkin bilgi tutum ve uygulamaları. Maltepe Üniversitesi Hemşirelik Bilim ve Sanatı Dergisi.2008;2:21-29.

12. Lai CKY, Chow SKY, Suen LKP, Wong IYC. The effect of a restraint reduction program on physical restraint rates in rehabilitation settings in Hong Kong. Rehabil Res Pract. 2011;1-9.

13. Bassi E, Ceresola M. Use of physical restraints in adult ICU patients to prevent patient-initiated device removal: a systematic review. JBI Libr Syst Rev. 2011;9(32 Suppl):1-14.

14. Kandeel NA, Attia AK. Physical restraints practise in adult intensive care units in Egypt. Nursing and Health Sciences.2013;15:79-85. 
15. Kahraman BB, Aşiret GD, Yıldırım G, Akyar I, Aytekin GK, Öz A. Yoğun bakımda fiziksel kısıtlamaya ilişkin hasta yakınlarının görüşleri. Yoğun Bakım Dergisi.2015;6:78-83.

16. Turgay AS, Sarı D, Genç RE. Physical restraint use in Turkish intensive care units. Clin Nurse Spec. 2009;23(2):68-72.

17. Krüger C, Mayer $H$, Haastert B, Meyer G. Use of physical restraints in acute hospitals in Germany: a multi-centre cross-sectional study. Int J Nurs Stud. 2013;50(12):1599-606.

18. De Jonghe $\mathrm{B}$, Constantin JM, Chanques G, Capdevila X, Lefrant JY. Physical restraint in mechanically ventilated ICU patients: a survey of French practice. Intensiv Care Med.2013;39(1):31-37.

19. Akansel N. Physical restraint practices among ICU nurses in one university hospital in weastern Turkey. J Health Sci.2007;1(4):7-13.

20. Huizing $A$, Hamers JP, Gulpers $M$ \& Berger $M$. Preventing the use of physical restraints on residents newly admitted to psycho-geriatric nursing home wards. Int J Nurs Stud. 2009;46:459-469.

21. Yan E, Kwok T, Lee D, Tang C. The prevalence and correlates of the use of restraint and force on hospitalised older people. Journal of Nursing and Health care of Chronic Illness.2009;1:147-155.

22. Registered Nurses' Association of Ontario. Promoting safety: Alternative approaches to the use of restraints [internet]. 2012 [Erişim Tarihi 20 Aralık 2016]. Erişim adresi: http://rnao.ca/sites/ rnaoca/files/Promoting_Safety_-

_Alternative_Approaches_to_the_Use_of_Restraints -0.pdf.

23. Rose L, Dale C, Smith OM, Burry L, Enright G, Fergusson D, Sinha S, WiesenfeldL, Sinuff T, Mehta S. A mixed-methods systematic review protocol to examine the use of physical restraint with critically ill adults and strategies for minimizing their use. Bio Med Central Syst Rev. 2016;5(194): 2-8.

24. Al-Khaled TH, Zahran EM, El-Soussi AH. Nurses' related factors influencing the use of physical restraint in critical care units. Journal of American Science. 2011;7(8):13-22.

25. Arslan S, Özer N. Yoğun bakım hastalarının duyusal girdi sorunlarında tamamlayıcı tedaviler. Anadolu Hemşirelik ve Sağlık Bilimleri Dergisi. 2010;13(2):6875.

26. Özdelikara A, Kaya E. Kısıtlama altındaki hastanın bakımında bir yol haritası. Yoğun Bakım Hemşireliği Dergisi. 2018;22(1):37-43.

27. Eskandari F, Abdullah KL, Zainal NZ, Wong LP. Incidence rate and patterns of physical restraint use among on adult patients in Malaysia. Clin Nurs Res. 2016;1-18.

28. Eşer I, Khorshid G, Hakverdioğlu G. The characteristics of physically restrained patients in intensive care units. International Journal of Human Sciences. 2007;4:1-12.

29. Jennet B, Teasdale G, Braakman R, Minderhoud J, Knill-Jones R. Predicting Outcome in Individual Patient safter Severe Head Injury. Lanset. 1976;1:1051-1056.

30. Sessler CN, Gosnell MS, Grap MJ, BrophyGM, O'Neal PV, Keane KA, Tesoro EP, Elswick RK. The Richmond Agitation- Sedation Scale: validity and reliability in adult intensive care unit patients. American Journal of Respiratory and Critical Care Medicine. 2002;166(10): 1338-1344.

31. Taha NM, Ali ZH. Physical restraints in critical care units: Impact of a training program on nurses' knowledge and practice and on patients' outcomes. J Caring Sci. 2013;2(2):1-9.

32. 32. Luk E, Sneyers B, Rose L, Perreault MM, Williamson DR, Mehta S, CookDJ, Lapinsky SC, Burry L. Predictors of physical restraint use in Canadian intensive care units. Crit Care. 2014;18(2):R46.

33. Gu T, Wang $X$, Deng $N$, Weng $W$. Investigating influencing factors of physical restraint use in China intensive care units: A prospective, cross-sectional, observational study. Australian Critical Care. 2019;32:193-198.

34. Van der Kooi AW, Peelen LM, Raijmakers RJ,Vroegop RL, Bakker DF, Tekatli H, van den Boogaard M, Slooter AJ. Use of physical restraints in Dutch intensive care units: a prospective multicenter study. Am J Crit Care. 2015;24(6):488-495.

35. Karagözoğlu Ş, Özden D, Vergi i. Hastanede çalışan hemşirelerde fiziksel tespit eğitim programının bilgi, tutum ve uygulamalarına etkisi. Türkiye Klinikleri. 2014;6(2):75-86.

36. Kısacık ÖG, Coşğun T. Evaluation of Physical Restraint Practices and Their Neurovascular Effect on Intensive Care Unit Patients. Yoğun Bakım Derg. 2019;10(2):110.

37. Kaya H, Dogu O. Intensive care unit nurses' knowledge, attitudes and practices related to using physical restraints. International Journal of Caring Sciences. 2018;11(1):61.

38. Huang $\mathrm{H}$, Chuang $\mathrm{Y}$, Chiang K. Nurses' physical restraint knowledge, attitudes, and practices: the effectiveness of an in-service education program. J Nurs Res. 2009;17(4):241-248.

39. Lai CKY, Chow SKY, Suen LKP, Wong IYC. Reduction of physical restraints on patients during hospitalisation/rehabilitation: a clinical trial. Asian J Gerontol Geriatr. 2013;8:38-43. 